Archive for

Organic Chemistry
Arkivoc 2017, part iv, 74-87

\title{
Phase transfer catalyzed conjugate addition-initiated ring-closure (CAIRC) reactions with 2-bromo-2-cyclopentenones
}

\author{
Alemayehu Mekonnen Yirsaw*a and Rolf Eric Carlson ${ }^{\text {b }}$ \\ ${ }^{a}$ Department of Chemistry, University of Bahir Dar, P.O.Box 79, Bahir Dar, Ethiopia \\ ${ }^{b}$ Department of Chemistry, University of Troms $\varnothing, N-9037$ Troms $\varnothing$, Norway \\ E-mail:yirsawnegaaleex@gmail.com
}

Received 10-25-2016

Accepted 04-16-2017

Published on line 05-07-2017

\section{Abstract}

When 2-bromo-2-cyclopentenone is treated with various carbon nucleophiles containing active methylenes, it undergoes a conjugate addition initiated-ring closure (CAIRC) reaction. This leads to the formation of carboand heterocyclic compounds in a regioselective fashion with good to high yield. Several bases and phase transfer catalysts were investigated. $\mathrm{CsF}-\mathrm{Si}(\mathrm{OEt})_{4}$ as base together with benzyldimethyl (2-hydroxyethyl)ammonium chloride, $\mathrm{C}_{6} \mathrm{H}_{5} \mathrm{CH}_{2} \mathrm{~N}(\mathrm{Cl})\left(\mathrm{CH}_{3}\right)_{2} \mathrm{CH}_{2} \mathrm{CH}_{2} \mathrm{OH}$, as phase transfer catalyst, were found to be mild and efficient reagents for carrying out the synthetic transformation

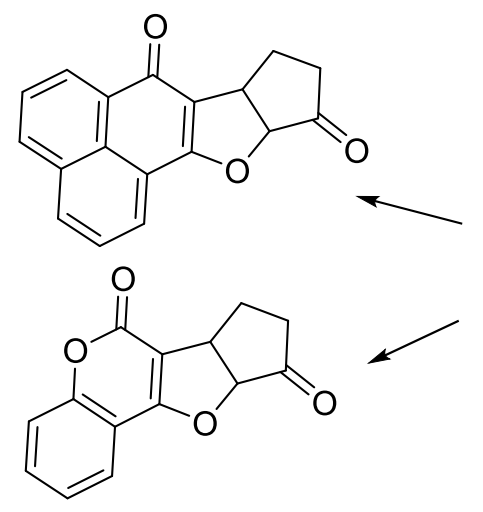<smiles>O=C1CCC=C1Br</smiles><smiles></smiles>

Keywords: Dihydrofurocoumarins, dihydrofurans, cyclopropanes, phase-transfer catalysis, tandem reactions, Michael acceptors, cesium-fluoride, tetraethyl orthosilicate 


\section{Introduction}

The synthesis of dihydrofurans and their derivatives has been of considerable interest to organic and medicinal chemists for many years as a large number of natural products and drugs contain this heterocyclic nucleus. For example, the dihydrofuran derivatives methyl 3,4-dihydro-2-methyl-4-oxo-2H-furo[3,2-c]chromene-2-carboxylate A, methyl 2,3,4,5-tetrahydro-2-methyl-4-oxofuro[3,2-c]quinoline-2-carboxylate B, methyl 8,9-dihydro-9-methyl-7-oxo-7H-phenaleno[1,2-b]furan-9-carboxylate C, 2-acetylnaphtho[2,3-b]furan4,9-dione D (Figure 1) and others having similar structures have been widely found in nature and they have also been synthesized. ${ }^{1}$ Amongst them a wide spectrum of biological activities is exhibited, including antimicrobial, antifungal, anticoagulant, insecticidal, anthelmintic, hypnotic, antidiuretic and antiarrhythmic properties. $^{2}$

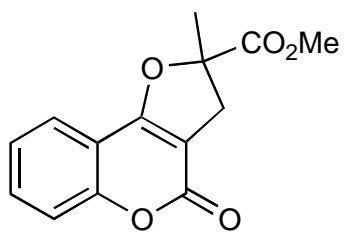

A

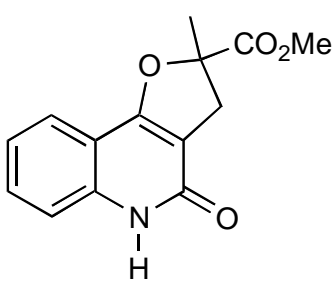

B

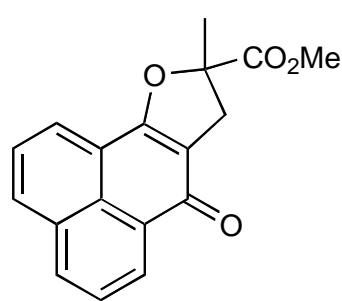

C

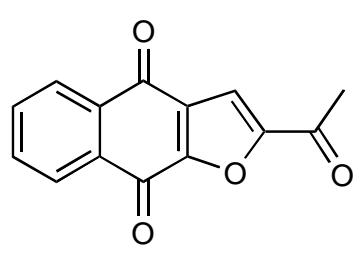

D

\section{Figure 1}

The development of more pharmacophores on these or related molecules might well lead to compounds with even better biological activity. ${ }^{3,4}$ In this regard, annulation methods have proved to be invaluable aids to synthetic chemists in the synthesis of such complex natural and non-natural products as terpenes, steroids, alkaloids and others. ${ }^{5,6}$

The use of CAIRC (conjugate addition initiated-ring closure), particularly phase transfer catalyzed tandem reactions for the synthesis of cyclopropane and dihydrofuran systems have only recently come of age as a simple straightforward one-pot synthesis and often these reactions are carried out under mild basic conditions. ${ }^{7,8}$ To a large extent, mild bases suppress the formation of side products, thus improving the yields of the desired products. ${ }^{9}$ Nonetheless, in many cases, the yields and scope of the reaction are far from satisfactory due to long reaction times that cause the decomposition of both reactants and products leading to reduced overall isolated yields. Moreover, the scope of the reaction with respect to nucleophiles is also limited since the indicated bases and phase transfer catalysts (PTC) provide no or only trace amounts of products when cyclic and bulky nucleophiles are used. ${ }^{10,11}$

Recently we discovered that CAIRC reactions in the presence of ionic liquids or Lewis acids could catalyze the formation of three and five-membered rings with good to high chemical yields by employing a variety of difunctional compounds. ${ }^{9,10}$ Our interest in extending and developing alternative protocols for CAIRC reactions, led us to explore phase-transfer catalysis. We found that a combination of CsF-Si(OEt) $)_{4}$ as base and $\mathrm{BnMe}_{2} \mathrm{~N}(\mathrm{Cl}) \mathrm{CH}_{2} \mathrm{CH}_{2} \mathrm{OH}$ as PTC was effective, giving tandem reaction in reduced reaction times, from days to hours. In particular, the utility of this reaction system is demonstrated by the preparation of polycyclic compounds having more complex structures, such as those listed below (Table 5), from commercially available starting materials. 
The present investigation was conducted in four steps: First, the screening of different bases under tetrabutylammonium bromide (TBAB) catalyzed reaction conditions. Second, the study of the influence of several PT catalysts in the presence of $\mathrm{K}_{2} \mathrm{CO}_{3}$ as the base. Third, a comparative study between bases $\left(\mathrm{K}_{2} \mathrm{CO}_{3}-\right.$ $\mathrm{NaHCO}_{3}$ and $\mathrm{CsF}-\mathrm{Si}(\mathrm{OEt})_{4}$ ) which gave promising results during the screening experiment, step a, in the presence of $\mathrm{BnMe}_{2} \mathrm{~N}(\mathrm{Cl}) \mathrm{CH}_{2} \mathrm{CH}_{2} \mathrm{OH}$ catalyst and, finally, investigation of the scope and limitations of the optimized reaction condition, using a wide range of nucleophiles.

\section{Results and Discussion}

The screening experiments were run with a number of commercially available PT catalysts and several inexpensive and mild inorganic and a few organic bases. By this methodology, both the base and the PTC work in tandem. This led to the development of an efficient protocol. Unless otherwise stated, in all the screening experiments, compounds $\mathbf{1} \mathbf{a}$ and $\mathbf{2 a - c}$ were used as model reagents. Toluene was used as the organic solvent and the reactions were run at room temperature. The yields obtained in the reaction of 1 a with several nucleophiles are given in Tables 1-5 and the reaction mechanism is summarized in Scheme $1 .{ }^{9}$

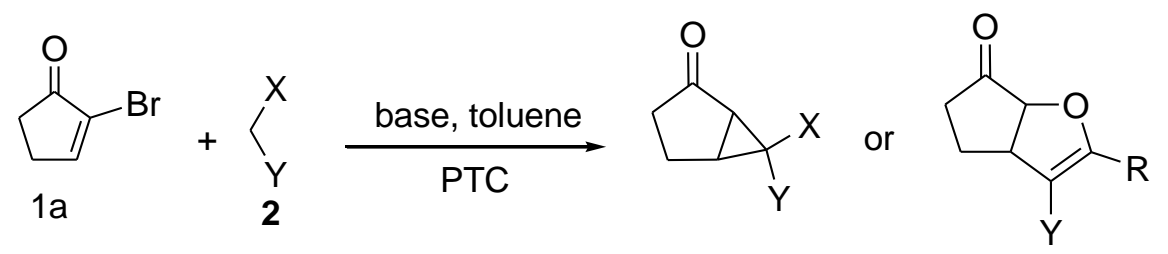

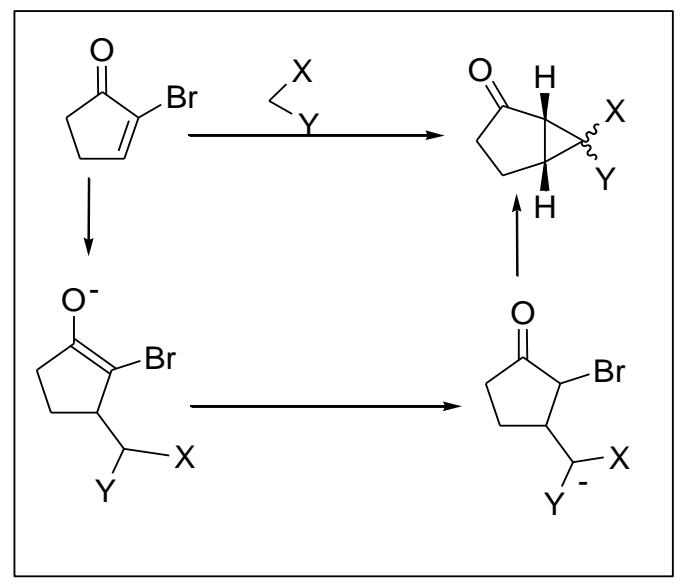

$\mathrm{Y}=\mathrm{X}=-\mathrm{CO}_{2} \mathrm{Me}$ or

$\mathrm{Y}=\mathrm{X}=-\mathrm{CN}$ or

$\mathrm{Y}=-\mathrm{CN}, \mathrm{X}=-\mathrm{CO}_{2} \mathrm{Me}$

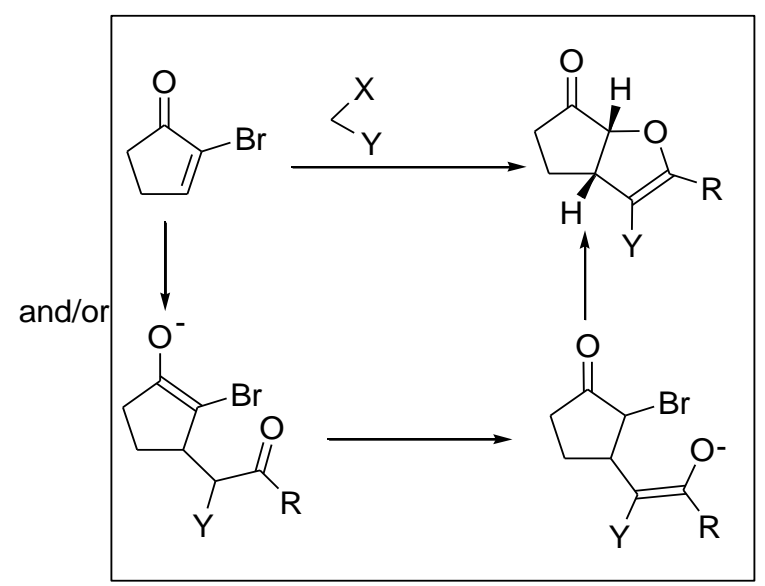

$\mathrm{Y}=-\mathrm{CO}_{2} \mathrm{Me}, \mathrm{X}=-\mathrm{COMe}$ or

$\mathrm{Y}=\mathrm{X}=-\mathrm{COMe}$

\section{Scheme 1}

\section{Screening of bases}

The effect of several bases on the tandem reaction of difunctional compounds (Figure 2) to 2-bromo-2cyclopentenone $1 \mathrm{a}$ in the presence of TBAB was studied (Table 1).

In this preliminary screening, we tested various organic and inorganic bases. The treatment of 1a with some dicarbonyl compounds at room temperature in toluene in the presence of TBAB and different inorganic 
bases gave tandem adducts in 63-88\% isolated yields. However, in the case of organic bases, the yield of the tandem product obtained from $\mathbf{2 a}$ was very low. For example, in the presence of $\mathrm{Et}{ }_{3} \mathrm{~N}$, the yield of $\mathbf{3 a}$ obtained was only $15 \%$ compared to $83 \%$ in the presence of $\mathrm{K}_{2} \mathrm{CO}_{3}$ (Table 1 , Entry 1 ) using the same reaction conditions. A similar phenomenon was also observed when $t$-BuOK was used. The reaction mixture with $\mathrm{t}$-BuOK/18crown-6 was messy; a number of degradation products were formed and we were not able to determine exactly what the product distribution was. We concluded that the higher basicity of alkoxide reagent favors the decomposition of the starting materials.

Based on this information, we continued to survey only inorganic bases such as $\mathrm{CsF}, \mathrm{Cs}_{2} \mathrm{CO}_{3}, \mathrm{Li}_{2} \mathrm{CO}_{3}, \mathrm{~K}_{2} \mathrm{CO}_{3}$, $\mathrm{NaHCO}_{3}, \mathrm{Na}_{2} \mathrm{CO}_{3}, \mathrm{CsF} / \mathrm{Si}(\mathrm{OR})_{4}$, etc., in the presence of TBAB. Both $\mathrm{Si}(\mathrm{OEt})_{4}$ and $\mathrm{Si}(\mathrm{OMe})_{4}$ were useful but $\mathrm{Si}(\mathrm{OEt})_{4}$ showed slightly better activity than $\mathrm{Si}(\mathrm{OMe})_{4}$. We also tested combinations of different bases to possibly find composite reagents that could improve the conversion.

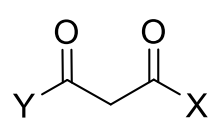

2 a. $X=O M e, Y=M e$

b. $X=Y=M e$

c. $X=Y=O M e$

d. $X=Y=C N$

e. $X=O M e, Y=C N$

\section{Figure 2}

Table 1. Effect of bases in the reaction of 1a with three nucleophiles in the presence of TBAB

\begin{tabular}{ccccc}
\hline Entry & Nucleophile & Base & Time/h & Yields/\% \\
\hline 1 & $\mathbf{2 a}$ & $\mathrm{K}_{2} \mathrm{CO}_{3}$ & 18 & $83(\mathbf{3 a})$ \\
2 & $\mathbf{2 a}$ & $\mathrm{Cs}_{2} \mathrm{CO}_{3}$ & 3 & 67 \\
3 & $\mathbf{2 a}$ & $\mathrm{K}_{2} \mathrm{CO}_{3}-\mathrm{NaHCO}_{3}$ & 14 & 88 \\
4 & $\mathbf{2 b}$ & $\mathrm{K}_{2} \mathrm{CO}_{3}$ & 14 & $81(\mathbf{3 b})$ \\
5 & $\mathbf{2 b}$ & $\mathrm{Cs}_{2} \mathrm{CO}_{3}$ & 2 & 82 \\
6 & $\mathbf{2 b}$ & $\mathrm{CsF}-\mathrm{Si}(\mathrm{OEt})_{4}$ & 10 & 86 \\
7 & $\mathbf{2 b}$ & $\mathrm{Cs}_{2} \mathrm{CO}_{3}-\mathrm{NaHCO}_{3}$ & 2 & 86 \\
8 & $\mathbf{2 b}$ & $\mathrm{K}_{2} \mathrm{CO}_{3}-\mathrm{NaHCO}_{3}$ & 14 & 84 \\
9 & $\mathbf{2 c}$ & $\mathrm{K}_{2} \mathrm{CO}_{3}$ & 20 & $77(\mathbf{3 c})$ \\
10 & $\mathbf{2 c}$ & $\mathrm{Cs}_{2} \mathrm{CO}_{3}$ & 3 & 63 \\
11 & $\mathbf{2 c}$ & $\mathrm{Cs}_{2} \mathrm{CO}_{3}-\mathrm{NaHCO}_{3}$ & 3 & 69 \\
12 & $\mathbf{2 c}$ & $\mathrm{CsF}^{-S}\left(\mathrm{OEt}_{4}\right.$ & 12 & 72 \\
13 & $\mathbf{2 c}$ & $\mathrm{K}_{2} \mathrm{CO}_{3}-\mathrm{NaHCO}_{3}$ & 20 & 84 \\
\hline
\end{tabular}

As summarized in Table 1, the best yields were obtained when reactions were mediated by $\mathrm{Cs}_{2} \mathrm{CO}_{3}, \mathrm{~K}_{2} \mathrm{CO}_{3}-$ $\mathrm{NaHCO}_{3}$, and $\mathrm{CsF}-\mathrm{Si}(\mathrm{OEt})_{4}$ (TEOS). The reactions went to completion in a short time (2-4 h) when $\mathrm{Cs}_{2} \mathrm{CO}_{3}$ or $\mathrm{Cs}_{2} \mathrm{CO}_{3}-\mathrm{NaHCO}_{3}$ were used. However, we found that $\mathrm{Cs}_{2} \mathrm{CO}_{3}$ mediated reactions also gave byproducts. The undesirable side reactions decreased the yields of the target adducts and rendered their purification difficult. Especially, this was a serious problem when the nucleophiles contained ester functionalities (Table 1, entries $2,10,11)$. Better results were obtained by employing either $\mathrm{CsF}-\mathrm{Si}(\mathrm{OEt})_{4}$ or $\mathrm{K}_{2} \mathrm{CO}_{3}-\mathrm{NaHCO}_{3}$. Although the combination of $\mathrm{K}_{2} \mathrm{CO}_{3}$ and $\mathrm{NaHCO}_{3}$ or $\mathrm{CsF}$ and $\mathrm{Si}(\mathrm{OEt})_{4}$ could lead to a drastic increase in rate of reaction and yield, neither of the bases alone was sufficiently effective to carry out the tandem reaction independently with 
TBAB as a phase-transfer catalyst. The tandem reaction did not proceed at all with $\mathrm{NaHCO}_{3}$ and $\mathrm{TBAB}$; only the starting materials were recovered even after prolonged reaction times.

\section{Screening of PT Catalysts}

To achieve an increased conversion rate, we further examined the effects of the PT catalysts on the tandem reaction using a selection of catalysts in the presence of $2 \mathrm{a}$ and $\mathrm{K}_{2} \mathrm{CO}_{3}$ (Scheme 2). The reason for choosing $\mathrm{K}_{2} \mathrm{CO}_{3}$ as a base in this screening was that $\mathrm{K}_{2} \mathrm{CO}_{3}$ is better with $\mathrm{TBAB}$ and any improvement using other catalysts could properly be associated with the activity of these catalysts. The performance of nine PT catalysts was compared (Table 2). The use of $\mathrm{BnMe}_{2} \mathrm{~N}(\mathrm{Cl}) \mathrm{CH}_{2} \mathrm{CH}_{2} \mathrm{OH}$ resulted in a unique and a remarkable increase in the rates of product formation and significantly enhanced chemical yield (Table 2, entry 5) while other catalysts such as THAB and TBABF were less effective, but still promising (Table 2, entries 2 and 3). Particularly, the catalytic effect of TBAB decreased when structurally more complex nucleophiles were used (Table 2, entry 1).<smiles>O=C1CCC=C1Br</smiles>

$1 \mathbf{a}$<smiles>COC(=O)CC(C)=O</smiles>

$2 a$
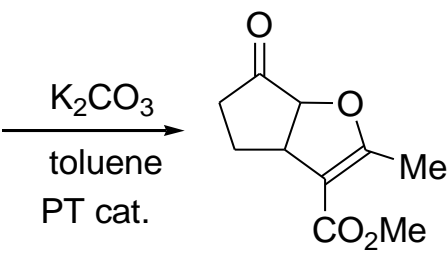

\section{Scheme 2}

Table 2. The role of different PT catalysts in the reaction of $1 \mathrm{a}$ with $2 \mathrm{a}$ in the presence of $\mathrm{K}_{2} \mathrm{CO}_{3}$

\begin{tabular}{ccc}
\hline Entry & PT catalyst & Yields $/ \%$ \\
\hline 1 & TBAB & 46 \\
2 & THAB & 69 \\
3 & TBABF & 67 \\
4 & TBAI & 54 \\
5 & $\mathrm{BnMe}_{2} \mathrm{~N}(\mathrm{Cl}) \mathrm{CH}_{2} \mathrm{CH}_{2} \mathrm{OH}$ & 81 \\
6 & $\left.\mathrm{BnN}^{\mathrm{Cl}}\right) \mathrm{Et}_{3}$ & 58 \\
7 & $\mathrm{Bu}_{4} \mathrm{NHSO}$ & 41 \\
8 & $\mathrm{BnP}(\mathrm{Cl}) \mathrm{Ph}_{3}$ & 52 \\
9 & $\mathrm{TBAF}$ & 34 \\
\hline
\end{tabular}

$\mathrm{TBAB}=$ tetrabutylammonium bromide, $\mathrm{THAB}=$ tetrahexylammonium bromide,

TBABF = tetrabutylammonium tetrafluoroborate, $T B A I=$ tetrabutylammonium iodide,

TBAF = tetrabutylammonium fluoride. The reaction time was $14 \mathrm{~h}$ in each case.

Although THAB afforded a reasonable yield, it required a longer reaction time since 1,4-adducts 5 were formed first and then slowly converted into the corresponding tandem products (Scheme 3). Fortunately, this was not found when a reactant like $\mathbf{2 c}$ that gave cyclopropanes was employed. 


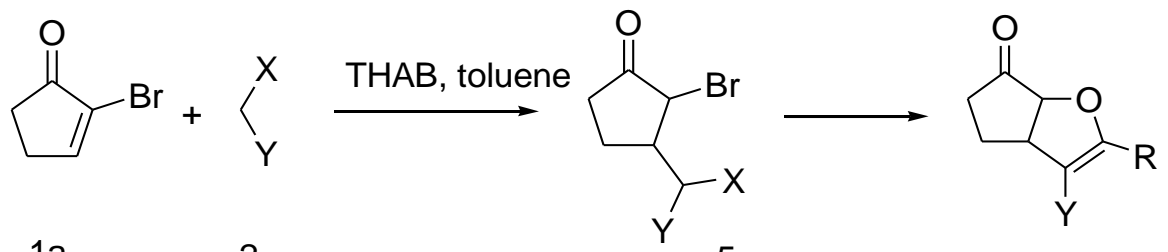

\section{Scheme 3}

Although the detailed mechanism of the reaction is not known with certainty, we interpret our findings as follows: The quaternary ammonium ion $\mathrm{Q}^{+}$from PTC coordinates to two O-atoms forming a stable sixmembered enolate. Thus, the catalyst functions in the formation of the desired product in the following ways: a) transfer of the enolate from an inter-phase to an organic phase and b) reaction of the enolate with the acceptor in the organic phase. Thus, the superior efficiency of $B n M e{ }_{2} \mathrm{~N}(\mathrm{Cl}) \mathrm{CH}_{2} \mathrm{CH}_{2} \mathrm{OH}$ could be interpreted in terms of organophilicity and accessibility of the lipophilic cation $\mathrm{Q}^{+}$of the catalyst. ${ }^{12}$ In other words, the PT agent must have enough lipophilicity to be able to partition the nucleophilic anion into the organic phase and the cation-anion interaction should be loose enough to ensure high anionic reactivity. ${ }^{13}$

\section{Comparative studies of $\mathrm{CsF}-\mathrm{Si}(\mathrm{OEt})_{4}$ and $\mathrm{K}_{2} \mathrm{CO}_{3}-\mathrm{NaHCO}_{3}$ as bases}

After finding that $\mathrm{BnMe}_{2} \mathrm{~N}(\mathrm{Cl}) \mathrm{CH}_{2} \mathrm{CH}_{2} \mathrm{OH}$ is the catalyst of choice for promoting our reactions, we applied this process to a series of nucleophiles to determine the scope and limitations with the base systems, $\mathrm{K}_{2} \mathrm{CO}_{3}-$ $\mathrm{NaHCO}_{3}$ and $\mathrm{CsF}-\mathrm{Si}(\mathrm{OEt})_{4}$. We found that the reaction rates were high and the chemical yields were increased by a factor of 1-2 when the tandem reaction was performed using simple, acyclic nucleophiles in the presence of either $\mathrm{K}_{2} \mathrm{CO}_{3}-\mathrm{NaHCO}_{3}$ or $\mathrm{CsF}-\mathrm{Si}(\mathrm{OEt})_{4}$ (Tables 3 and 4). However, it should be emphasized that $\mathrm{K}_{2} \mathrm{CO}_{3}-\mathrm{NaHCO}_{3}$ became less efficient as the complexity of the nucleophile increased and, in most cases, $\mathrm{CsF}-\mathrm{Si}(\mathrm{OEt})_{4}$ afforded distinctly superior results in shorter reaction times.

Although the synthesis of dihydrofurans using the $\mathrm{K}_{2} \mathrm{CO}_{3}-\mathrm{NaHCO}_{3}$ procedure was found to be useful for a range of acyclic nucleophiles, it afforded poor yields with the cyclic analogs. For example, $\mathbf{2 f}$ gave only $10 \%$ conversion after $12 \mathrm{~h}$ of stirring (Table 3, entry 6) and attempts to perform the reaction with $\mathbf{2} \mathbf{h}-\mathbf{2} \mathbf{k}$ failed. Surprisingly, $2 \mathrm{~g}$ gave a high yield of the corresponding dihydrofuran in the presence of $\mathrm{K}_{2} \mathrm{CO}_{3}-\mathrm{NaHCO}_{3}\left(\mathrm{Table}_{3}\right.$, entry 7 ). This exceptional reactivity of $\mathbf{2} \mathbf{g}$ towards $\mathbf{1 a}$ was also observed during ionic liquid promoted synthesis of dihydrofurans. ${ }^{9}$ Reaction of $1 \mathbf{a}$ with $\beta$-diesters like $\mathbf{2 c}$ was slow and complete conversion was obtained only after $24 \mathrm{~h}$ in the presence of $\mathrm{K}_{2} \mathrm{CO}_{3}-\mathrm{NaHCO}_{3}$ (Table 3, entry 3).

\section{Scope and limitations using $\mathrm{CsF}-\mathrm{Si}(\mathrm{OEt})_{4}$}

In this investigation, the efficiency of $\mathrm{CsF}-\mathrm{Si}(\mathrm{OEt})_{4}$ can be explained as: electron density at Si decreases with extra-coordination, causing the electropositive character (Lewis acidity) of the silicon center to be increased. ${ }^{14}$ In addition, electronegative substituents can also lower the energy of the $3 \mathrm{~d}$ atomic orbitals, which facilitates the formation of hypervalent silicon compounds. As outlined in Scheme 4, silicon can adopt 4, 5 and 6 coordinate complexes (Scheme 4). Nucleophilicity of ligands, particularly R, attached to Si center increases from 4 to 6 -coordinate complexes. ${ }^{15}$ 
Table 3. Effects of $\mathrm{K}_{2} \mathrm{CO}_{3}-\mathrm{NaHCO}_{3}$ on the Michael acceptor $1 \mathrm{a}$ and donors in the presence of $\mathrm{BnMe}{ }_{2} \mathrm{~N}(\mathrm{Cl}) \mathrm{CH}_{2} \mathrm{CH}_{2} \mathrm{OH}$

Entry

${ }^{a}$ A single diastereomer was obtained

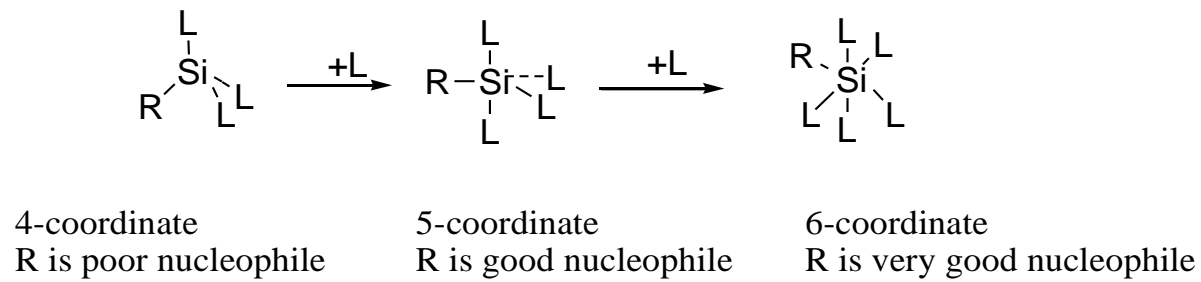

\section{Scheme 4}

Accordingly, $\mathrm{Si}(\mathrm{OEt})_{4}$ is a prototypical alkoxide and its applications exploit the reactivity of the Si-OR bonds. The catalytic effect of $\mathrm{F}^{-}$involves the displacement of an $\mathrm{OR}^{-}$via an $\mathrm{S}_{\mathrm{N}} 2-\mathrm{Si}$ mechanism followed by preferential 
abstraction of a proton from the base by the $\mathrm{RO}^{-}$. In addition to biphasic activity, the PTC can also temporarily coordinate with the reagents as a Lewis acid to facilitate proton abstraction (Scheme 5). ${ }^{16}$

\section{Possible mechanism for $\mathrm{CsF}-\mathrm{Si}(\mathrm{OEt})_{4}$ mediated CAIRC reactions}
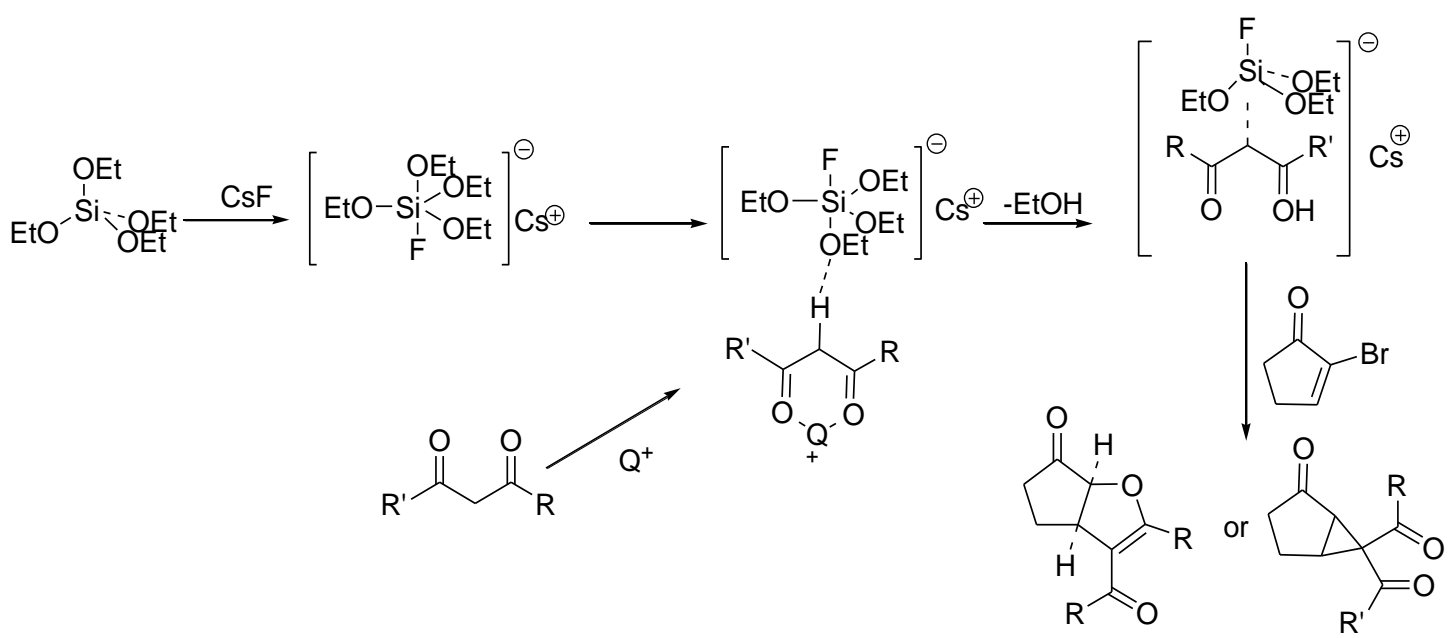

\section{Scheme 5}

After having identified a suitable base system and an efficient PT catalyst that afforded efficient conversion, the reactions between $\mathbf{1 a}$ or $\mathbf{1} \mathbf{b}$ and a range of nucleophiles $\mathbf{2} \mathbf{a}-\mathbf{2} \mathbf{k}$ were run. Across this range of nucleophiles, the yields and rate of conversion were uniformly good (Table 4).

When 1a was treated with $\mathbf{2 a}$ in the presence of $\mathrm{CsF}-\mathrm{Si}(\mathrm{OEt})_{4}$ and a catalytic amount of $\mathrm{BnMe}_{2} \mathrm{~N}(\mathrm{Cl}) \mathrm{CH}_{2} \mathrm{CH}_{2} \mathrm{OH}$, methyl 4,5,6,6a-tetrahydro-2-methyl-6-oxo-3aH-cyclopenta[b]furan-3-carboxylate 3a was formed in good yield (Table 4 , entry 1 ). Likewise, when $\mathbf{2 b}$ was treated with $\mathbf{1 a}$, only the corresponding dihydrofuran $\mathbf{3 b}$ was isolated in quantitative yields. As shown in Table 4, entries 3, 4 \& 5, the reaction of $\mathbf{2 c}$, $\mathbf{2 d}$ and $\mathbf{2 e}$ with $\mathbf{1 a}$ also proceeded smoothly to give the desired cyclopropane derivatives $\mathbf{3 c}, \mathbf{3 d}$ and $\mathbf{3 e}$, respectively, with relatively short reaction times. Particularly, $\mathbf{2 e}$ undergoes a highly diastereoselective reaction to give only one isomer of $3 e$.

Based on these findings, we have extended our study of the reaction of compound 1a with cyclic $\beta$ dicarbonyl compounds such as $\mathbf{2 f}$ and $\mathbf{2 g}$ as a possible means for the synthesis of tricyclic dihydrofuran adducts $\mathbf{3 f}$ and $\mathbf{3 g}$. The yields obtained were good (Table 5, entries 1 and 2 ). The superiority of CsF-Si(OEt) $)_{4}$ and $\mathrm{BnMe}_{2} \mathrm{~N}(\mathrm{Cl}) \mathrm{CH}_{2} \mathrm{CH}_{2} \mathrm{OH}$ over other combinations for the tandem reaction was further demonstrated by using some other representative bulky nucleophiles, $\mathbf{2 h - 2 k}$ (Figure 3), which led to the preparation of dihydrofurocoumarin and other derivatives of natural products (Scheme 6). Due to solubility problems with some of the nucleophiles, acetonitrile was used as a solvent instead of toluene in the reaction between $\mathbf{1 a}, \mathbf{1} \mathbf{b}$ and 4-hydroxycoumarin $2 \mathrm{~h}, 2$,4-quinolinediol $\mathbf{2 i}$, 3-hydroxy-1H-phenalen-1-one $\mathbf{2} \mathbf{j}$ and 2-hydroxy-1,4naphthoquinone $\mathbf{2 k}$. 
Table 4. Effects CsF-Si(OEt $)_{4}$ on the Michael acceptors $\mathbf{1 a}, \mathbf{1} \mathbf{b}$ and a range of donors in the presence of $\mathrm{BnMe}_{2} \mathrm{~N}(\mathrm{Cl}) \mathrm{CH}_{2} \mathrm{CH}_{2} \mathrm{OH}$

Entry<smiles>O=C1CCCC(=O)C1</smiles>

$2 f$<smiles>O=C1CC(=O)c2ccccc21</smiles>

$2 g$<smiles>O=c1cc(O)c2ccccc2o1</smiles>

$2 \mathrm{~h}$<smiles>Oc1cc(O)c2ccccc2n1</smiles>

$2 i$<smiles>O=C1C=C(O)c2cccc3cccc1c23</smiles>

2j<smiles>O=C1C=C(O)C(=O)c2ccccc21</smiles>

$2 k$

Figure 3

For instance, the reaction of $\mathbf{1 a}$ with $\mathbf{2} \mathbf{h}$ and $\mathbf{2} \mathbf{i}$ gave the potentially biologically interesting dihydrofurocoumarin $3 \mathrm{~h}$ and dihydrofuroquinolinone derivative $3 \mathrm{i}$ in 58 and $56 \%$ yields, respectively, without formation of any regioisomers (Table 5 , entries 3 and 4 ). Treatment of $\mathbf{2} \mathbf{j}$ with $\mathbf{1 a}$ gave the expected dihydrofurophenalenone $\mathbf{3} \mathbf{j}$ in high yield and in a reasonably short time (Table 5 , entry 5 ). Similarly, $\mathbf{2 h}$ reacted with $\mathbf{2 -}$ bromo-2-cyclohexenone $\mathbf{1 b}$ to furnish $\mathbf{4 h}$ in $61 \%$ yield. The nucleophiles $\mathbf{2} \mathbf{i}$, and $\mathbf{2} \mathbf{j}$ also reacted smoothly with $\mathbf{1 b}$ as Michael acceptor under the same conditions to give $\mathbf{4 i}$, and $\mathbf{4 j}$ in 59 and $87 \%$ isolated yields, respectively (Scheme 6). Surprisingly, when $\mathbf{1 a}$ and $\mathbf{1} \mathbf{b}$ were treated with $\mathbf{2 k}$, dihydrofuronaphthoquinone adducts $\mathbf{3 k}$ and $\mathbf{4 k}$ were obtained (Table 5, entries 6 and 10). They were, however, highly unstable and decomposed into nonhomogenous mixtures upon attempted isolation. They could only be identified by GC-MS. 


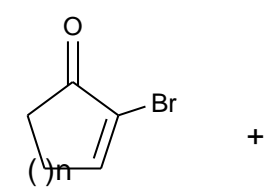

$\mathrm{n}=1, \mathbf{1 a}$

$=2, \mathbf{1 b}$<smiles>O=C1C=C(O)c2cccc3cccc1c23</smiles><smiles>O=C1C2=CC=CC2C2=C1OC1(CCCCC1=O)O2</smiles>

$\mathrm{CH}_{3} \mathrm{CN}$

\section{Scheme 6}

The longer reaction times required for cyclic compounds compared to those of acyclic $\beta$-diketones could be explained as a result of formation of unstable complexes due to steric compression or due to increased negative charge delocalization. In general, the results in Table 5 indicate that $\mathrm{CsF}-\mathrm{Si}(\mathrm{OEt})_{4}$ with $\mathrm{BnMe}_{2} \mathrm{~N}(\mathrm{Cl}) \mathrm{CH}_{2} \mathrm{CH}_{2} \mathrm{OH}$ is the most efficient combination that can be applied to a wide range of reagents, particularly for diesters and cyclic nucleophiles and it provides a rapid route for the preparation of a variety of polycycles and heterocycles.

Table 5. Effects of CsF-Si(OEt $)_{4}$ on the Michael acceptors $\mathbf{1 a}, \mathbf{1} \mathbf{b}$ and range of donors (2f-2k) in the presence of $\mathrm{BnMe}_{2} \mathrm{~N}(\mathrm{Cl}) \mathrm{CH}_{2} \mathrm{CH}_{2} \mathrm{OH}$

Entry Acceptor Time/hoophile


Table 5. Continued

Entry Acceptor Time/h

\section{Conclusions}

Since tandem transformation is among the most efficient synthetic routes, development of reaction conditions that use non-toxic, readily available, mild and economic reagents with operational simplicity could contribute to the creation of environmentally benign processes. To this end, we have demonstrated that $\mathrm{CsF}-\mathrm{Si}(\mathrm{OEt})_{4}$ and $\mathrm{BnMe}_{2} \mathrm{~N}(\mathrm{Cl}) \mathrm{CH}_{2} \mathrm{CH}_{2} \mathrm{OH}$ mediated reactions are simple, efficient, clean, highly regioselective processes that give high yields with structurally diverse difunctionals reagents such as $\beta$-diesters, $\beta$-diketones, $\beta$-ketoesters, nitroesters, malononitriles, and cyanoesters in reasonable reaction times. They give single products and in these cases no further purification was necessary. An advantage of using CsF-Si(OEt) $)_{4}$ is also that it is not necessary most to use a stoichiometeric amount of $\mathrm{CsF}$; only $20 \mathrm{~mol} \%$ and a stoichiometric amount of $\mathrm{Si}(\mathrm{OEt})_{4}$ is sufficient to give the reaction. In $\mathrm{CsF}-\mathrm{Si}(\mathrm{OEt})_{4}$ mediated reactions, $\mathrm{Si}(\mathrm{OEt})_{4}$ plays two roles: First, generation of a strong base, $\mathrm{C}_{2} \mathrm{H}_{5} \mathrm{O}$, capable of deprotonating the difunctional compound, which is promoted by coordination of $\mathrm{F}^{-}$to the Si-compound. Second, trapping of the enolate adduct by the silyl enol ether and then transfer of the Michael acceptor for 1,4-addition to occur.

The reaction system could probably be further extended for the regioselective synthesis of naturally occurring and biologically active polycyclic compounds containing the dihydrofuran motif, which are otherwise difficult to prepare by other methods. To the best of our knowledge, this is the first example of a general base mediated PT catalyzed tandem reaction of various dicarbonyl compounds to enones.

\section{Experimental Section}

General. All ${ }^{1} \mathrm{H}$ and ${ }^{13} \mathrm{C}$ NMR spectra were recorded on a JEOI JNM-EX 400 FT-NMR system using $\mathrm{CDCl}_{3}$ as a solvent at room temperature. Chemical shifts are given in ppm and J-values in $\mathrm{Hz}$. Analytical TLC were carried 
out on precoated $(0.25 \mathrm{~mm})$ Merck silica gel F-254 plates. Flash chromatography was carried out using matrix silica (Si-60 ̊ 35-70 $\mu \mathrm{m}$ ). GLC analyses were performed on a Varian 3300 chromatograph equipped with split injector, FID detector and a Varian 4400 integrator. IR spectra were recorded on a FT-IR spectrometer and are reported as wave number. GC-MS spectra were registered on a Hewlett 5890 Packard series II CP Sil 5 CB column $(25 \mathrm{~m})$ followed by VG Quattro mass spectrometer. A Finnigan-MAT-95XL mass spectrometer was used to obtain HREIMS data and the spectra were obtained at $250{ }^{\circ} \mathrm{C}$ and $70 \mathrm{eV}$. All reagents and solvents except 2-bromoenones 1 were obtained from commercial sources and used as received without further purification. 2-Bromoenones $\mathbf{1} \mathbf{a}, \mathbf{b}$ were prepared according to literature procedure. ${ }^{13}$

General procedure for the screening experiments. A mixture of $1 \mathbf{a}$ or $\mathbf{1 b}(1.0 \mathrm{mmol})$, a reagent $2 \mathrm{a}-\mathrm{c}(1.25$ $\mathrm{mmol})$, a base $(1 \mathrm{mmol})$ and PT catalyst $(15 \mathrm{mmol} \%)$ in toluene $(5 \mathrm{~mL})$ was stirred for the specified time at room temperature (Tables 1 and 2). The organic product was extracted with $\mathrm{Et}_{2} \mathrm{O}$. The combined organic layers were washed with brine and dried over $\mathrm{Na}_{2} \mathrm{SO}_{4}$. The solvent was removed in vacuo and the residue purified with column chromatography using appropriate solvents to get the required products.

Procedure for the reaction of $\mathbf{2 - b r o m o e n o n e s ~ ( 1 a ~ a n d ~} \mathbf{1 b}$ ) with various carbon nucleophiles $\mathbf{2 a - 2 k}$. A mixture of $1(1.0 \mathrm{mmol})$ and a reagent $2(1.25 \mathrm{mmol})$ in the presence of CsF $(20.0 \mathrm{mmol} \%), \mathrm{Si}(\mathrm{OEt})_{4}(1 \mathrm{mmol})$ and $\mathrm{BnMe}_{2} \mathrm{~N}(\mathrm{Cl}) \mathrm{CH}_{2} \mathrm{CH}_{2} \mathrm{OH}(15.0 \mathrm{mmol} \%)$ in toluene or $\mathrm{CH}_{3} \mathrm{CN}(5 \mathrm{ml})$ was stirred for the specified time at room temperature (Table 4). The organic product was extracted with EtOAc or $\mathrm{CHCl}_{3}(3 \mathrm{x})$. The combined organic layers were washed with brine and dried over $\mathrm{Na}_{2} \mathrm{SO}_{4}$. The solvent was removed in vacuo and the residue purified with column chromatography using appropriate solvents to get the required products. Products $\mathbf{3 a - 3 g}$ have been known but $\mathbf{3 h}-\mathbf{3} \mathbf{j}$ and $\mathbf{4 h - 4} \mathbf{j}$ were unknown compounds ${ }^{9}$ and their spectral data are given below.

7,8-Dihydro-6bH,9aH-5,10-dioxa-pentaleno[2,1-a]naphthalene-6,9-dione (3h). Yield 0.142 g, 58\%; brown powder, $\mathrm{R}_{f} 0.41$ (4:1 EtOAc/ $\mathrm{CHCl}_{3}$ ); $\mathrm{mp} 294-295{ }^{\circ} \mathrm{C}$. IR (neat, $\mathrm{NaCl}$ plates, $\mathrm{v}_{\max } \mathrm{cm}^{-1}$ ): 3143, 2995, 1732, 1715, 1645, 1569, 1382; ${ }^{\mathrm{H}}$ NMR: $\delta$ 2.46--2.61 (m, 2H), 2.68--2.75 (m, 2H), 4.20--4.38 (m, $\left.1 \mathrm{H}\right), 5.13(\mathrm{~d}, J 8.8 \mathrm{~Hz}, 1 \mathrm{H})$, $7.19(\mathrm{t}, J 10.0 \mathrm{~Hz}, 1 \mathrm{H}), 7.29--7.49(\mathrm{~m}, 1 \mathrm{H}), 7.61(\mathrm{t}, J 6.8,1 \mathrm{H}), 7.71(\mathrm{dd}, J 6.4 \& 1.2 \mathrm{~Hz}, 1 \mathrm{H}) ;{ }^{13} \mathrm{C} \mathrm{NMR:} \delta 24.6\left(\mathrm{CH}_{2}\right)$, $33.5\left(\mathrm{CH}_{2}\right), 42.0(\mathrm{CH}), 87.6(\mathrm{CH}), 112.3(\mathrm{C}), 124.1(\mathrm{CH}), 124.8(\mathrm{CH}), 127.5(\mathrm{C}), 130.1(\mathrm{CH}), 133.9(\mathrm{CH}), 155.4(\mathrm{C})$, 160.2 (C), 163.3 (COO-), 202.4 (CO); HRMS found for $\mathrm{C}_{14} \mathrm{H}_{10} \mathrm{O}_{4}$ : 242.0578. calcd: 242.0579.

5,6b,7,8-Tetrahydro-9aH-10-oxa-5-aza-pentaleno[2,1-a]naphthalene-6,9-dione (3i). Yield 0.137 g, 56\%, white powder, $\mathrm{R}_{f} 0.38$ (4:1 EtOAc/ $\mathrm{CHCl}_{3}$ ), mp 400-402 ${ }^{\circ} \mathrm{C}$. IR (neat, $\mathrm{NaCl}$ plates, $\mathrm{v}_{\max }, \mathrm{cm}^{-1}$ ): 3155, 2982, 1735, 1697, $1658,1563,1335,1307,1221 ;{ }^{1} \mathrm{H}$ NMR: $\delta$ 2.18-2.24 (m, 2H), 2.28-2.45 (m, 2H), 4.33-4.46 (m, $\left.1 \mathrm{H}\right), 5.06(\mathrm{~d}, J$ $8.8 \mathrm{~Hz}, 1 \mathrm{H}), 7.22(\mathrm{t}, J 10.0 \mathrm{~Hz}, 1 \mathrm{H}), 7.38-7.54(\mathrm{~m}, 1 \mathrm{H}), 7.65(\mathrm{t}, J 6.4 \mathrm{~Hz}, 1 \mathrm{H}), 7.73(\mathrm{~d}, J 8.0 \mathrm{~Hz}, 1 \mathrm{H}), 11.85(\mathrm{~s}, 1 \mathrm{H}) ;{ }^{13} \mathrm{C}$ NMR: $\delta 23.7\left(\mathrm{CH}_{2}\right), 35.1\left(\mathrm{CH}_{2}\right), 41.8(\mathrm{CH}), 85.9(\mathrm{CH}), 108.9(\mathrm{C}), 112.2(\mathrm{C}), 116.4(\mathrm{CH}), 122.7(\mathrm{CH}), 123.0(\mathrm{CH})$, $126.4(\mathrm{CH}), 131.6$ (C), 154.2 (C), 163.4 (CON), 213.2 (CO); HRMS found for $\mathrm{C}_{14} \mathrm{H}_{11} \mathrm{NO}_{3}$ : 241.0731. calcd: 241.0738.

8,9-Dihydrocyclopenta[d]phenaleno[1,2-b]furan-7,10(7bH,10aH)-dione (3j). Yield $0.234 \mathrm{~g}$, 84 \%, yellow solid; $\mathrm{R}_{f} 0.34$ (4:1 EtOAc/ $\mathrm{CHCl}_{3}$ ), $\mathrm{mp} 356-358.6^{\circ} \mathrm{C}$. IR (neat, $\mathrm{NaCl}$ plates, $\mathrm{v}_{\max } \mathrm{cm}^{-1}$ ): 3181, 2991, 1745, 1728, 1673, 1560, 1475, 1320; ${ }^{1} \mathrm{H}$ NMR: $\delta$ 2.22--2.36 (m, 2H), 2.38--2.47 (m, 2H), 4.23--4.30 (m, $\left.1 \mathrm{H}\right), 5.04(\mathrm{~d}, J 9.2 \mathrm{~Hz}, 1 \mathrm{H})$, $7.53(\mathrm{t}, J 7.8 \mathrm{~Hz}, 1 \mathrm{H}), 7.61--7.70(\mathrm{~m}, 2 \mathrm{H}), 8.06--8.16(\mathrm{~m}, 2 \mathrm{H}), 8.62(\mathrm{~d}, J 7.6 \mathrm{~Hz}, 1 \mathrm{H}) ;{ }^{13} \mathrm{C} \mathrm{NMR:} \delta 24.9\left(\mathrm{CH}_{2}\right), 36.3$ $\left(\mathrm{CH}_{2}\right), 43.0(\mathrm{CH}), 86.8(\mathrm{CH}), 110.5(\mathrm{C}), 127.3(2 \times \mathrm{CH}), 128.1(2 \times \mathrm{CH}), 128.4 .(\mathrm{C}), 129.3(\mathrm{C}), 131.2(\mathrm{C}), 133.1(\mathrm{CH})$, 133.8 (C), 134.6 (CH), 135.7(C), 161.8 (CO), 202.6 (CO); HRMS found for $\mathrm{C}_{18} \mathrm{H}_{12} \mathrm{O}_{3}: 276.0787$. calcd: 276.0786.

6a,8,9,10a-Tetrahydro-7H-benzo[4,5]furo[3,2-c]chromene-6,10-dione (4h). Yield 0.157 g, 61\%, brown solid, $\mathrm{R}_{f}$ 0.46 (3:2 EtOAc/ $\mathrm{CHCl}_{3}$ ), mp 319-321.4 ${ }^{\circ} \mathrm{C}$. IR (neat, $\mathrm{NaCl}$ plates, $\mathrm{V}_{\max } \mathrm{cm}^{-1}$ ): 3153, 2999, 1730, 1718, 1642, 1560, 1382, 1192; ${ }^{1} \mathrm{H}$ NMR: $\delta$ 1.92--2.06 (m, 2H), 2.18--2.38 (m, 2H), 2.52--2.64 (m, 2H), 4.10--4.15 (m, $\left.1 \mathrm{H}\right)$, $5.29(\mathrm{~d}, J 10.0 \mathrm{~Hz}, 1 \mathrm{H}), 7.10(\mathrm{~d}, J 7.6 \mathrm{~Hz}, 1 \mathrm{H}), 7.20--7.34(\mathrm{~m}, 1 \mathrm{H}), 7.48(\mathrm{t}, J 6.8 \mathrm{~Hz}, 1 \mathrm{H}), 7.80(\mathrm{dd}, J 7.6$ \& $1.3 \mathrm{~Hz}, 1 \mathrm{H})$; 
${ }^{13} \mathrm{C}$ NMR: $\delta 21.7\left(\mathrm{CH}_{2}\right), 25.2\left(\mathrm{CH}_{2}\right), 38.1\left(\mathrm{CH}_{2}\right), 42.9(\mathrm{CH}), 87.8(\mathrm{CH}), 104.3(\mathrm{C}), 112.3(\mathrm{C}), 117.3(\mathrm{CH}), 124.2(\mathrm{CH})$, $124.5(\mathrm{CH}), 129.8(\mathrm{CH}), 133.2(\mathrm{CH}), 156.0(\mathrm{C}), 168.4(\mathrm{COO}), 206.2(\mathrm{CO})$; HRMS found for $\mathrm{C}_{15} \mathrm{H}_{12} \mathrm{O}_{4}: 256.0739$. calcd: 256.0736.

6a,8,9,10a-Tetrahydro-5H,7H-11-oxo-5-azabenzo[a]fluorene-6,10-dione (4i). Yield $0.152 \mathrm{~g}$, 59\%, white solid, $\mathrm{R}_{\mathrm{f}} 0.40$ (3:2 EtOAc/ $\mathrm{CHCl}_{3}$ ), $\mathrm{mp} 413-415{ }^{\circ} \mathrm{C}$. IR (neat, $\mathrm{NaCl}$ plates, $v_{\max } \mathrm{cm}^{-1}$ ): 3142, 2988, 1728, 1703, 1655, 1543, 1321, 1287; ${ }^{1} \mathrm{H}$ NMR: $\delta$ 1.94-2.13 (m, 2H), 2.20--2.32 (m, 2H), 2.56--2.65 (m, 2H), 4.18--4.32 (m, 1H), $5.26(\mathrm{~d}, J 9.6 \mathrm{~Hz}, 1 \mathrm{H}), 7.20(\mathrm{t}, J 7.2 \mathrm{~Hz}, 1 \mathrm{H}), 7.46--7.51(\mathrm{~m}, 1 \mathrm{H}), 7.65(\mathrm{t}, J 6.8 \mathrm{~Hz}, 1 \mathrm{H}), 7.78(\mathrm{~d}, J 8.0 \mathrm{~Hz}, 1 \mathrm{H}), 11.55$ (s, $1 \mathrm{H}) ;{ }^{13} \mathrm{C}$ NMR: $\delta 21.8\left(\mathrm{CH}_{2}\right), 26.4\left(\mathrm{CH}_{2}\right), 38.9\left(\mathrm{CH}_{2}\right), 44.4(\mathrm{CH}), 88.1(\mathrm{CH}), 117.8(\mathrm{C}), 124.2(\mathrm{CH}), 124.6(\mathrm{CH})$, $126.9(\mathrm{CH}), 133.2(\mathrm{CH}), 134.0$ (C), 140.6 (C), 161.5 (C), 164.3 (CO), 207.8 (CO); HRMS found for $\mathrm{C}_{15} \mathrm{H}_{13} \mathrm{NO}_{3}$ : 255.0897. calcd: 255.0895.

7a,9,10,11a-Tetrahydro-8H-12-oxaindeno[2,1-a]phenalene-7,11-dione (4j). Yield 0.255 g, 87\%, yellow powder, $\mathrm{R}_{\mathrm{f}} 0.37$ (3:2 EtOAc/ $\left.\mathrm{CHCl}_{3}\right), \mathrm{mp} 370-371.8^{\circ} \mathrm{C}$. IR (neat, $\mathrm{NaCl}$ plates, $\left.\mathrm{v}_{\max }, \mathrm{cm}^{-1}\right): 3181,3001,1738,1726$, $1673,1585,1465,1321,1230 ;{ }^{1} \mathrm{H}$ NMR: $\delta$ 1.94--2.13 (m, 2H), 2.20--2.34 (m, 2H), 2.39--2.48 (m, 2H), 4.25--4.32 $(\mathrm{m}, 1 \mathrm{H}), 5.04(\mathrm{~d}, J 9.2 \mathrm{~Hz}, 1 \mathrm{H}), 7.51(\mathrm{t}, J 7.8 \mathrm{~Hz}, 1 \mathrm{H}) 7.58--7.72(\mathrm{~m}, 2 \mathrm{H}), 8.07--8.17(\mathrm{~m}, 2 \mathrm{H}), 8.64(\mathrm{~d}, J 7.6 \mathrm{~Hz}, 1 \mathrm{H})$; ${ }^{13} \mathrm{C}$ NMR: $\delta 21.8\left(\mathrm{CH}_{2}\right), 25.2\left(\mathrm{CH}_{2}\right), 36.4\left(\mathrm{CH}_{2}\right), 43.3(\mathrm{CH}), 86.6(\mathrm{CH}), 111.2(\mathrm{C}), 127.1(2 \times \mathrm{CH}), 128.3(2 \times C H)$, 128.4. (C), 130.1 (C), 131.5 (C), 133.0 (CH), 133.6 (C), 134.8 (CH), 135.9 (C), 162.0 (CO), 202.5 (CO); HRMS found for $\mathrm{C}_{19} \mathrm{H}_{14} \mathrm{O}_{3}$ : 290.0944. calcd: 290.0945.

\section{Acknowledgements}

The authors thank the Norwegian Research Council for financial support and Mr. John Vedde at the Institute of Chemistry, University of Oslo, for obtaining HREIMS data.

\section{References}

1. Wu, C.; Johnson, R. K.; Mattern, M. R.; Wong, J. C.; Kingston, D. G. I. J. Nat. Prod. 1999, 62, 963-968. https://doi.org/10.1021/np9900019

2. Christov, V. Ch.; Ismailov, I. E.; Ivanov, I. K. Molecules, 2015, 20, 7263-7275

https://doi.org/10.3390/molecules20047263

3. Kilroy, T. G.; O’Sullivan, T. P.; Guiry, P. J. Eur. J. Org. Chem. 2005, 4929-4949. https://doi.org/10.1002/ejoc.200500489

4. Loopes, R, C. V.; Oliveira M. C. F,; Lemos T. L. G.; Mattos M. C. J. Braz. Chem. Soc. 2005, 16, 1048-1053.

5. Hagiwara, H.; Sato, K.; Nishino, D.; Hoshi, T.; Suzuki, T.; Ando, M. J. Chem. Soc. Perkin Trans. I 2001, 2946$-2957$.

https://doi.org/10.1039/b107180g

6. Calter, M. A.; Zhu, C. Org. Lett. 2002, 4, 205-208. https://doi.org/10.1021/ol0169978

7. Farina, F.; Maestro, M. C.; Martin, M. V.; Soria, M. L. Tetrahedron 1987, 43, 4007-4014. https://doi.org/10.1016/S0040-4020(01)81683-5

8. Chen, C.; Liao, Y.; Huang, Y.-Z. Tetrahedron 1989, 45, 3011-3020. https://doi.org/10.1016/S0040-4020(01)80128-9

9. Mekonnen, A.; Carlson, R. Synthesis 2006, 1657-1663.

10. Arai, S.; Nakayama, K.; Ishida, T.; Shioiri, T. Tetrahedron Lett. 1999, 40, 4215-4218. 
https://doi.org/10.1016/S0040-4039(99)00679-6

11. Arai, S.; Nakayama, K.; Suzuki, Y.; Hatano, K-I.; Shioiri, T. Tetrahedron Lett. 1998, 39, 9739-9742. https://doi.org/10.1016/S0040-4039(98)02239-4

12. Starks, C. M.; Liotta, C. L.; Halpern, M. Phase-transfer catalysis: fundamentals and industrial application perspectives, Chapman \& Hall, 1994; pp 1-122.

https://doi.org/10.1007/978-94-011-0687-0 1

13. Naik, S. D.; Doraiswamy, L. K. AlChE Journal 1998, 44, 612-646.

https://doi.org/10.1002/aic.690440312

14. Kowalski, C. J.; Weber, A. E.; Fields, K. W. J. Org. Chem. 1982, 47, 5088-5093. https://doi.org/10.1021/jo00147a008

15. Corriu, R. J. P.; Perz, R.; Reye, C. Tetrahedron 1983, 39, 999-1009. https://doi.org/10.1016/S0040-4020(01)88599-9

16. Ahn, K. H.; Lee, S. J. Tetrahedron Lett. 1994, 35, 1875-1878. https://doi.org/10.1016/S0040-4039(00)73184-4 